DOI: $10.14451 / 1.171 .80$

\title{
ИННОВАЦИОННАЯ АКТИВНОСТЬ И АГРОТЕХНОПАРКИ В СЕЛЬСКОХОЗЯЙСТВЕННОМ СЕКТОРЕ КАК ОСНОВА РОСТА ОТРАСЛИ
}

\author{
(c) 2019 Трутнев Даниил Мурманович \\ аспирант \\ Институт государственной службы и управления \\ Российская академия народного хозяйства и государственной службы \\ при Президенте Российской Федерации \\ 119571, Москва, просп. Вернадского, 82 \\ E-mail: trutnevdm@bk.ru
}

В статье рассматриваются теоретические подходы в определении инновационной активности, показывается ряд тенденций в развитии аграрного сектора и предлагается один из способов повышения использования инноваций в отечественном сельском хозяйстве.

Ключевые слова: инновации, инновационная деятельность, сельское хозяйство, наука, агротехнопарки.

Скорость происходящих изменений в обществе и мире, а также быстрое развитие технологий затрагивают все сферы жизни. Эта быстрота перемен, в особенности технологических и социальных, изменила роль инноваций в условиях постоянной конкуренции между производителями разных масштабов, будь то мелкие хозяйства или международные корпорации, и даже вопрос благополучия и развития государств, для которых экономические успехи залог процветания. Всё это требует концентрирования на проблемах создания и внедрения новых знаний и технологий, а также приспособления уже существующих структур под постоянно изменяющиеся реалии окружающего мира [1].

Согласно исследованиям использование инноваций в сельском хозяйстве составляет около $3-4 \%$, что мало даже по сравнению с другими отраслями российской экономики - к примеру, в промышленности этот же критерий составляет 9,2\% [8]. И совершенно понятно, что такая ситуация тормозит темпы развития аграрного сектора как в отдельных регионах так и в стране в целом.

В данном русле важно наладить связь между научным, образовательным и производственным комплексом, а также государством. Важной платформой в этом деле могут стать агротехнопарки и бизнес-инкубаторы [2].

Инкубаторы (бизнес-инкубаторы) - комплексы, осуществляющие поддержку новообразованным инновационным компаниям на этапе их возникновения и становления путём оказания разного рода услуг. Инкубаторы призваны

помочь этим инновационным фирмам пройти самый непростой период - период «детства» в наиболее благоприятных условиях, с мягкими условиями аренды помещений, оборудования, получением информационной и консультационной поддержки и иных видов. Всё это должно способствовать их выживаемости и переходу в дальнейшее «взрослое» состояние. Помимо приведённых выше льгот бизнес-инкубаторы осуществляют и прочие виды услуг, такие как:

- помощь в ведении бухгалтерии и учредительных документов;

- поддержка в проведении маркетинговых исследований;

- поиск инвесторов и иных источников финансирования;

- консультации по технологической части;

- способствование повышению предпринимательской грамотности [3];

- распространение энерго- и ресурсосберегающих технологий и их внедрение в сельскохозяйственное производство [4].

При рассмотрении вопросов инновационной деятельности следует для начала обозначить определение этого понятия.

Для начала приведём определение данное Росстатом.

«Инновационная деятельность - вид деятельности, связанный с трансформацией идей (обычно результатов научных исследований и разработок либо иных научно - технических достижений) в технологически новые или усовершенствованные продукты или услуги, внедренные на рынке, в новые или усовершенство- 
ванные технологические процессы или способы производства (передачи) услуг, использованные в практической деятельности» [9].

Вот какое определение даёт ОЭСР: «Инновационной деятельностью являются все научные, технологические, организационные, финансовые и коммерческие этапы, которые фактически или по замыслу ведут к созданию инноваций. Некоторые могут быть новейшими, другие наоборот не новыми, но всё же необходимыми для претворения в жизнь инноваций. Инновационная деятельность также включает НИОКР, которые не связаны напрямую с конкретной разрабатываемой инновацией» [10].

Как можно увидеть, определение ОЭСР по сравнению с Росстатом выделило звенья инновационной деятельности, у каждого из которых есть свои особенности, зачастую сильно отличающиеся от других. Понимание этого может поспособствовать более эффективному принятию решений по работе с инновациями с государственного уровня с учётом наличия сети разных элементов, осуществляющих инновационную деятельность. Отдельно упомянуты, не связанные напрямую с некой данной инновацией, НИОКР. Здесь стоит отметить разработки не только смежных инноваций, но и фундаментальные исследования, направленных на получение общих знаний, на основе которых потом проводятся уже разные исследования и разработки прикладного характера. То есть, фундаментальные исследования не всегда связаны напрямую с конкретной инновацией, часто выражающейся в конечном виде как товар или услуга, но так или иначе оказали на её создание определённое воздействие.

В числе положительных факторов, влияющих на инновационную активность в сельском хозяйстве, выделяется:

- наличие выхода на мировой рынок сель- хозпродукции с растущим спросом на неё;

- растущий экспорт продовольствия из России;

- санкции на ввоз продовольствия из ряда стран;

- политика импортозамещения, в первую очередь в аграрном секторе;

- доступ к зарубежному рынку технологий и оборудования, невысокие пошлины на их ввоз;

- достаточное количество земельных ресурсов в стране [5].

К отрицательным можно причислить:

- высокую конкуренцию на мировом рынке;

- снизившийся в последние годы внутренний спрос [6];

- увеличившиеся цены на зарубежные технологии вследствие девальвации рубля;

- неконкурентоспособность немалой части отечественной продукции.

Одним из главнейших препятствий к увеличению участия инноваций в аграрном секторе является недостаточное финансирование сельскохозяйственных наук со стороны государства. В 2013 году финансирование сельскохозяйственной науки в России составило 268 млн. \$ [6].

Затраты на исследования в сельском хозяйстве были значительно увеличены лишь после появления срочной необходимости в замещении импортных продуктов питания в связи с начавшимся в 2014 году политическим конфликтом с рядом стран перекинувшимся на прочие сферы. Но даже это увеличение можно объяснить скорее эффектом низкой базы, также стоит вспомнить резкую девальвацию российского рубля [7]. Вдобавок доля расходов на НИОКР в сельскохозяйственной секторальной инновационной системе (СИС с.х.) упала в общей доле затрат на НИОКР (рисунок 1).

Как можно видеть из табл. 1 уровень затрат

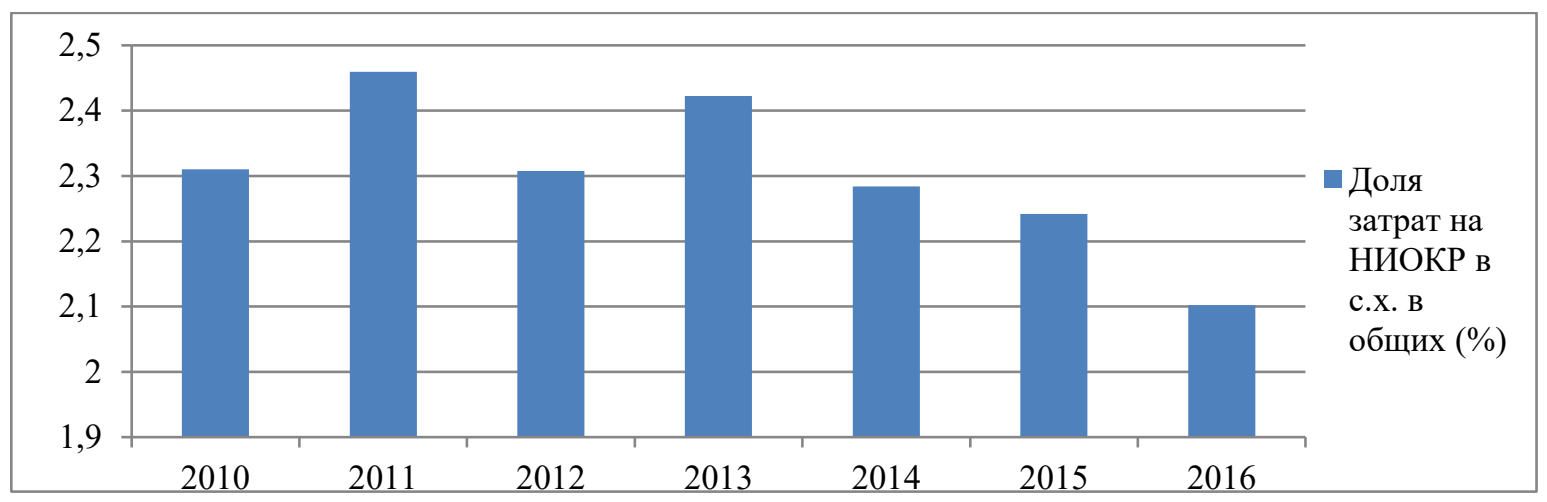

Puc. 1. Изменение доли затрат на НИОКР в с.х. в общем объёме (\%) Источник. Росстат. 
Таблица 1. Уровень затрат на сельскохозяйственную СИС в России (млн.у.е.)

\begin{tabular}{|c|c|c|c|c|c|c|c|c|c|}
\hline & \multicolumn{9}{|c|}{ Годы } \\
\hline Валюта & 2008 & 2009 & 2010 & 2011 & 2012 & 2013 & 2014 & 2015 & 2016 \\
\hline Рубль, РФ & 22235 & 27435 & 25427 & 29062 & 30225 & 33611 & 26247 & 34080 & 20802 \\
\hline Доллар, США & 894 & 863 & 837 & 988 & 973 & 1055 & 680 & 556 & 310 \\
\hline
\end{tabular}

Источник. Статистические данные с сайта ОЭСР.

URL: https://stats.oecd.org/Index.aspx? DataSetCode=MON2017_REFERENCE_TABLE

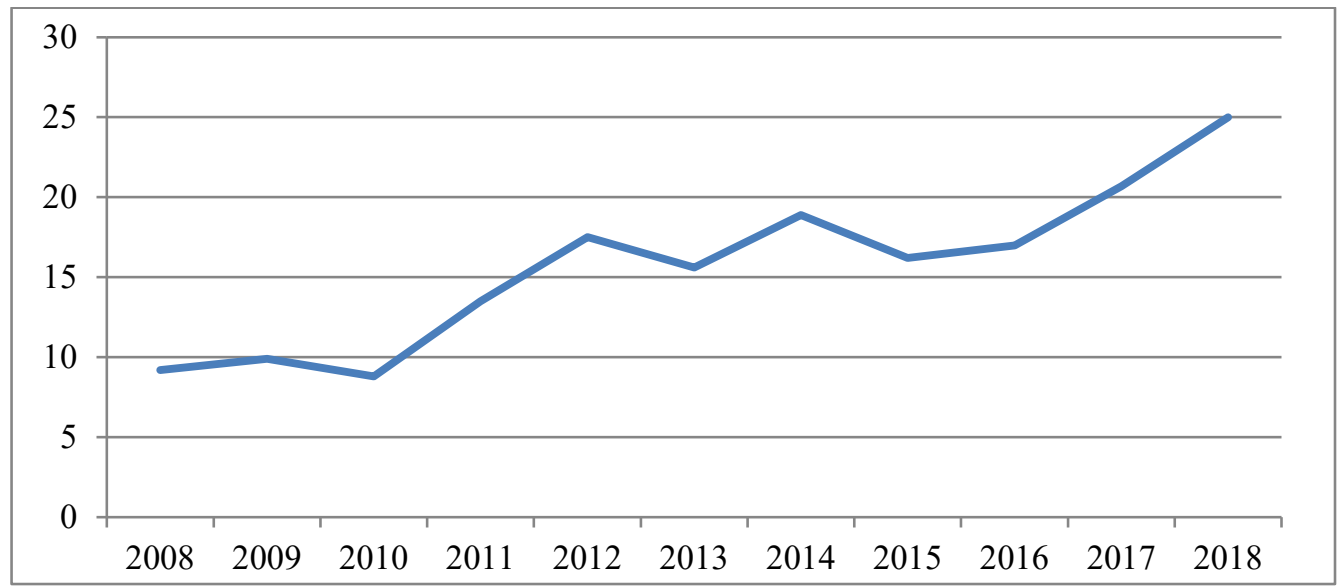

Puc. 2. Объём экспорта продовольствия из России в период 2008-2018 гг. (млрд. долл. США) Источник. Росстат.

Интернет-портал «Агровестник» URL: https://agrovesti.net/lib/industries/ob-eksporte-selkhozsyrya-i-prodovolstviya-iz-rossii-v-2001-2018-gg.html

на СИСс/х не повысился, зато уровень производства продовольствия вырос настолько, что его экспорт стал четвёртым в общей доле вывозимых товаров после нефтегазовой, металлургической и химической отраслей, обогнав при этом экспорт продукции военно-промышленного комплекса. Если в 2016 году экспорт продовольствия составлял 16,2 млрд. \$, то в 2018 году достиг 25 млрд. \$, таким образом вырос в 1,5 раза (рисунок 2).

Вышеуказанное даёт основание рассуждать о том, что рост производства продовольствия и его экспорта идёт во многом экстенсивным путём, чем за счёт применения инноваций. В дальнейшем это может обернуться исчерпанием резервов для количественного роста и, как следствие, снижением роста отрасли. В настоящее время уже в силе научно-техническая программа развития АПК до 2025 года [11]. В ней есть позиции, предусматривающие увеличение затрат на сельскохозяйственную науку. В ней правда не прописано создание агротехнопарков, основной упор делается на разработки семян и племенного материала, что в общем-то тоже немало, так как целый ряд растительных культур и пород животных зависят более чем на 80\% от зарубежных поставок, что в условиях противостояния с рядом стран и мировой нестабильностью в целом может нести угрозу безопасности страны.

\section{Библиографический список}

1. Гапоненко Н.В. Сфера исследований и разработок в эпоху фундаментальных изменений. // Информационное общество. 2006. № 6.

2. Новиков И.С. Формирование и функционирование инновационных интегрированных структур (агротехнопарков) в системе “производство-образование-наука": диссертация ... кандидата экономических наук: 08.00.05 / Новиков Иван Сергеевич; [Место защиты: Сарат. гос. аграр. ун-т им. Н.И. Вавилова]. Саратов. 2016. $195 \mathrm{c}$.

3. Толмачева Н., Оксанич Н. Роль сельскохозяйственной потребительской кооперации при переходе мелкотоварного производства на инновационную модель развития // Междунар. с.-х. журн. 2008. № 6. С. 17-19. 
4. Фоломьев А. Обоснование инновационного типа воспроизводства // Экономист. 2005. № 8. С.40-47

5. Бортникова И.М. Механизм учета инновационной деятельности в сельскохозяйственных организациях // Фундаментальные исследования. 2014. № 11 (часть 7). С. 1585-1588 (1638).

6. Шагайда Н.И., Узун В.Я. Тенденции развития и основные вызовы аграрного сектора России: аналитический доклад. Москва. 2017. 89.с.

7. Трутнев Д.М. Генерирование знаний в секторальной инновационной системе в области сельского хозяйства: финансовые проблемы // Вестник Евразийской науки. 2018. № 6. https://esj.today/PDF/04ECVN618.pdf.

8. Интернет-журнал «Агроинвестор» URL: https://www.agroinvestor.ru/technologies/news/28575-lish-3-4predpriyatiy-apk-primenyayut-innovatsii/

9. Росстат. URL: http://www.gks.ru/free_doc/new_site/business/nauka/minnov-1.htm

10. OECD, 2005, “The Measurement of Scientific and Technological Activities: Guidelines for Collecting and Interpreting Innovation Data: Oslo Manual, Third Edition” prepared by the Working Party of National Experts on Scientific and Technology Indicators, OECD, Paris, paras. 40, 42

11. Интернет-портал Правительства РФ URL: http://government.ru/docs/29004/

Поступила в редакцию 14.01.2019 